\title{
Debate
}

\section{Would Aristotle have played Russian Roulette?}

\author{
John Harris The Centre for Social Ethics and Policy, University of Manchester
}

\begin{abstract}
This paper continues the debate between myself and Peter Singer et al started in the Journal of Medical Ethics volume 21, no 3 about the ethical respectability of the use of QALYs in health care allocation. It discusses the question of what, in the way of health care provision, would be chosen by rational egoists behind a Rawlsian "veil of ignorance", and takes forward the vexed question of what is to count as "doing good" and hence as "doing the most good" in health care. Most importantly, this paper argues that it would be unfair to discriminate against people because they have been disadvantaged by their genetic condition. It notes that McKie et al in their reply to my first contribution to this debate continue to fail to distinguish between chance and probability and it is argued that this failure causes them to miss the whole point of the argument.
\end{abstract}

In their rejoinder" to my paper "Double jeopardy and the veil of ignorance" John McKie, Peter Singer, Helga Kuhse and Jeff Richardson (hereafter McKie et al) concentrate on two main issues. ${ }^{2}$ The first is on whether or not Rawls's "veil of ignorance" device supports QALYs as a method of prioritisation in the delivery of health care. The second is their disagreement with the fundamental principle that each person is entitled to the equal concern, respect and protection of the community, McKie et al, holding that it is not persons who have this entitlement, but rather units of quality adjusted lifetime, abstractly conceived.

There are three main areas of disagreement between us. The first is that we have different views about what is to count as "doing good" and hence as "doing the most good" in health care. So that, for example, when they say that my approach "violates, not just in a minor way, but in a big way, the principle that we should allocate resources so as to do the most good" they are just begging the question at issue between us.

\section{Key words}

Doing good; Rawls; beneficial health care; QALYs.
Secondly, we have different views about what sort of person the person behind the veil of ignorance is, and what she would choose under conditions of ignorance. They see her as a utility maximiser, I see her, as Rawls did, as a risk-averse rational egoist.

Finally, we have different views about what life is like behind the veil of ignorance. I'll try to say something about all these issues in what follows.

We'll start behind the veil of ignorance with the issue of what people deprived of self-knowledge would agree to be the method of resource allocation for health care most likely to serve their own personal interests.

\section{The calculations of probability}

McKie and his co-authors suggest that I have made what they call "an elementary error" in suggesting that "a rational egoist would surely only give preference to saving the life of the person with the highest interest in continued existence, when he is also most likely to be that person. If he has no better than a 50/50 chance of being that person it cannot be in his interests to prioritise the life of such a person because he cannot know that he won't in fact be worsening his own chances; the same goes for nonlife saving gains". Now I don't want to get bogged down in arguing about how to calculate the precise percentage chance, for as McKie et al concede, this is only important on the assumption that it makes sense to talk about people having a greater or lesser interest in continuing alive. A point I decidedly reject.

Moreover people cannot calculate their chances of either needing particular kinds of medical help nor their chances of receiving it from behind the veil of ignorance because, by hypothesis, they lack the requisite knowledge. For example, anyone's chances of having a higher QALY rating than the people with whom he or she is in competition for resources will depend on such things as the age balance of the relevant population and the distribution of genetic endowments. So, whatever percentage chance is mentioned it is, of necessity, arbitrary. This is their claim: 
"Whether treatment is offered according to QALY principles or randomly, since it is only offered to one patient, you have a $50 \%$ chance of being the patient who receives no treatment and dies. Since this is common to both methods of allocation, the rational egoist could disregard it. But similarly, on both methods of allocation you have a $50 \%$ chance of being the patient whose life is saved. Then what the rational egoist is offered if treatment is allocated according to QALY principles is a $50 \%$ chance of getting a big utility gain (having your life saved when you will have a long life of good quality). On the other hand what the rational egoist is offered if the treatment is allocated randomly is a $25 \%$ chance of the same big utility gain and a $25 \%$ chance of a small utility gain (life-saving treatment when you will die within a few days anyway). ${ }^{3}$

First, it is important to note that this is a highly tendentious way of putting things. The contrast is not between a chance (whatever percentage chance it is) of "a long life of good quality" on the one hand, and a chance of "dying in a few days anyway" on the other. In their original response to me, Singer et al ${ }^{4}$ suggested that I tried to make things easy for myself, but this is surely a case of pots and kettles! The contrast, as McKie et al make a point of pride in their reply (except where emphasis on the point would weaken their case), may well often be between large and slightly larger utility gains, between a long life of good quality and a slightly longer life of good quality.

\section{Group dynamics}

After the veil is lifted there is a group who consist of higher and lower QALYs. They are $100 \%$ of the population. Of these, only some smaller percentage will ever be in competition for treatment with others where not all can be treated. If QALYs are the allocative principle used, $50 \%$ of that population of competitors for treatment will be higher QALYs ${ }^{5}$ and all will survive; or to put it another way, 50\% only will be eligible to survive, and will survive, and all will be higher QALYs. If, as I advocate, random selection procedures are used to determine treatment once the veil is lifted, then all will be eligible and again, $50 \%$ will survive and will consist of high and low QALYs.

If you end up in this group it is true you may find yourself with larger or smaller utility. But, and this point is of the first importance, if you are one of those who find yourself with the chance of survival, but with smaller utility, it is not true that had you chosen QALYs you would have had a larger utility, nor a larger chance of a larger utility. Had you chosen QALYs you would be dead already! The way McKie et al put things encourages the belief that you, the individual, are choosing a method that will give you personally $25 \%$ more chance of a larger utility than you

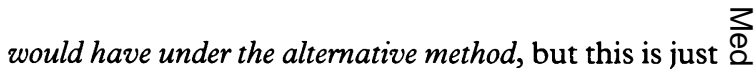
not true.

What is true of course, is that the survivors, as a group, will have larger total and average utility than under a method that shows no preference to the for- $\overrightarrow{\vec{N}}$ tunate, but since behind the veil they have no reason $\frac{0}{7}$ to suppose they are more likely to be in the group of the fortunate than in the other group, they will only $\frac{\bar{\sigma}}{\bar{c}}$. choose QALYs if they wish to ensure the survival of $\vec{\nabla}$ the fortunate, that is if they are utility maximisers and not risk-averse rational egoists.

\section{Only two can play}

So much for the situation where the choice is between the population of candidates for care. If we $\overparen{\Phi}$ concentrate on individual choices, where two people $N$ are candidates and only one of the two can be treated, then again, there is no error of the sort attributed to me by McKie et al, and QALYs remain an unattractive method of choice. People behind the veil know that once the veil is lifted they may be in competition with one other person for a scarce chance of life-saving therapy. One of those two people will inevitably have a higher QALY score than the other, so, using QALYs at the point of choice once the veil is lifted, one has $100 \%$ certaint of treatment and the other has no chance at all. On random method each always has a $50 \%$ chance continuing such life as is available to them with treatment. Each has a $50 \%$ chance of the best that life can offer them given their condition.

There is also a massive psychological charge on the point of real choice beyond the veil of ignorance. At that point, in the hospital weighting (sic) area, the prognosis will have two elements: the chance of remission with treatment and the chance of getting treatment given the level of remission available. In a world that respects persons equally, my world, the patient will be told: "You have a relatively poor prognosis but you will have the same chance as anyone else of getting the therapy that will help you". In McKie et al's meritocracy of the fortunate the patient should be told: "You have a relatively poor prognosis and because someone else has a slightly (or greatly) better prognosis there is nothing more that we will do for you". Note that the doctor cannot say that there is nothing more that we can do for you.

McKie et al have been paying fast and loose. The person behind the veil is, by hypothesis, a rational egoist. Such individuals are presumed, certainly by Rawls, to be risk-averse. The risk-averse weigh the ? down side more than the upside. What risk-averse rational egoists want behind the veil is the best chance of not being the ones who fail to benefit from treatment by any selection procedure used once the veil is lifted.

Behind the veil the choosers cannot know what their chances of being someone with the prospect of 
higher QALYs following treatment are, nor can they know what their chances of treatment are if the QALY method becomes the selection procedure; so they have no reason to advantage those with such a prospect, nor those whom the QALY method will prefer. This was and is my point. So my statement "a rational egoist would surely only give preference to saving the life of the person with the highest interest in continued existence when he is also more likely to be that person"6 seems unexceptionable.

\section{Rawlsian choice}

Behind the veil of ignorance the Rawlsian rationalegoist chooser is supposed to (and would surely) reason thus: "I cannot know that when the veil is lifted I won't turn out to be one of the least well off in the society which emerges, I must therefore make the position of the least well off person as good as it can possibly be". It is this reasoning which leads Rawls to his famous difference principle. The rational egoist is thus, as we have noted, essentially risk-averse. When contemplating her chances from behind the veil of ignorance the rational egoist must choose the method of resource allocation that will govern her prospects for treatment. We are just considering two possible methods: a QALY or a random approach.

The rational egoist, I have supposed, will reason as follows: "I must suppose that the worst outcome might befall $m e$ and that the chances of this happening are sufficiently high that I ought to consider it as a real possibility. The worst outcome on either method is that I will turn out to have lower rather than higher QALY expectations. I will have a $50 \%$ chance of what is (of necessity in my case) a smaller utility gain. But what is the alternative? On the QALY method of allocation the worst outcome for me is no chance at all, certain death." I maintain that a Rawlsian rational egoist would prefer a worst case scenario which still gives a $50 \%$ chance of survival to a worst case scenario which gives no chance at all.

The thinking behind my using the figure of $50 \%$ was the following, but the point is the same on McKie et al's preferred calculation. If QALYs are used as the allocative procedure, only $50 \%$ of the population will be eligible for survival. If random methods are used $100 \%$ will be eligible. In each case $50 \%$ will survive. Would the rational egoist opt for a method where only $50 \%$ of the population have a chance of survival and he has no reason to suppose he will be in that privileged $50 \%$, rather than a method where $100 \%$ have a chance and he knows he will be one of those with a chance because all have a chance?

McKie $e t$ al, talk as if each person has a chance of being a survivor and of having either a $50 \%$ chance of a large utility gain on one method or a $25 \%$ chance of being a lucky survivor and $25 \%$ chance of being an unlucky survivor. But in reality on McKie et al's preferred method some are agreeing, blind, to have no chance at all.

The question people behind the veil should put to themselves is: should I opt for a selection procedure that may exclude me entirely, or one which, at the point of selection, always gives me a $50 \%$ chance?

Ironically, McKie et al have conceded that they accept that this way of choosing is precisely what rational egoists behind the veil would use. When discussing whether or not Aristotle endorsed slavery, thinking he himself might be enslaved following defeat in war, McKie et al explicitly state that: "First, if Aristotle endorsed slavery in the knowledge that he might be disadvantaging himself - in the knowledge that he was making his own situation worse ${ }^{7}$ - then he was not choosing as a rational egoist ... In the real world, rational egoists would only support slavery if they knew for certain ${ }^{8}$ that they would be among the masters and not the slaves". My point exactly! In the real world people would only choose QALYs if they knew for certain that they would be QALY rich; they would never choose QALYs if there was a chance that they would have lower QALYs, for in that case they would die. ${ }^{9} \mathrm{McKie}$ et al's point is that slavery is so bad that it would only be chosen by people who were certain they would never be slaves. My point is that having no chance at all of treatment and hence in many cases, of being offered no chance at all of life, is so bad that any method of resource allocation? that would involve this, would likewise only be chosen by people who were sure that they would not be among those offered no chance. So only people sure they would not have low QALYs would choose QALYs as the method of allocation.

The whole McKie et al position depends on convincing us that people behind the veil would be utility maximisers rather than Rawlsian risk-averse rational egoists. But what they say about Aristotle's reasoning demonstrates that they believe that Aristotle would not be a utility maximiser but would be riskaverse. This both concedes my interpretation of how people would choose behind the veil of ignorance and so also concedes that such people would reject a policy of maximising QALYs.

\section{Better lives and lives more worthy to be lived}

McKie et al are missing the point about interpersonal comparisons of quality of life, which their example about comparisons between different persons in pain goes no way to resolve. I do not deny that it makes sense to say that my life would be better if I was healthier, happier and more successful. I do not deny that it might make sense to say that Peter's life is healthier, happier and more successful than mine (if it is). What I deny is that it follows from such judgments that either my life is more worth 
saving if its quality improves, than it was before, or that Peter's life is more worth saving than mine if he is healthier, happier and more successful than me.

A meal of bread and water is not the less worth eating than a meal of pre-phylloxera claret and plovers' eggs, if each is the only meal on offer and the only meal that will prevent starvation. In such a context it makes no sense to argue about which meal is the more worth eating. Or, rather you have to specify more worth eating from what perspective given what objective. And this is true even if it is an objective fact that the latter is universally preferred and objectively preferable. ${ }^{10}$ Suppose John and Peter are each affected by a condition which makes a particular diet imperative if they are to stay alive. John's diet, unhappily for him, consists solely of bread and water, Peter can survive only on pre-phylloxera claret and plovers' eggs. It does not follow from the fact that John would be happier with Peter's condition, that there is a greater moral imperative to feed Peter, if resources can only purchase food for one, but not both, of them. In conceding that claret and plovers' eggs is a pleasanter diet than bread and water. John is not conceding that Peter's life is more valuable than his nor, to use McKie et al's preferred terminology, that Peter has a greater interest in living. ${ }^{11} \mathrm{~A}$ life on the bread line is no less worth saving than a life on the egg line.

This does not of course show that some lives are not more valuable than others. It shows only that it does not follow from the fact that some lives are more desirable in virtue of their objective features than others, that those with more desirable lives have more valuable lives.

Each person has a powerful interest in living his own life - the life available to him. Each person has a powerful interest in making that life as good as it can be. In striving to make my life more like Peter's, I am not conceding that Peter's is more valuable in what I have called the "existential" sense, more worth living, more worthy to be lived. These are different senses of terms such as "worth" and "value". McKie et al have made a virtue of a sensitive position which can identify and use minute $\vec{\circ}$ differences in quality and quantity of life. It has the consequence however that we must believe that those who are, for example, richer and more successful have a greater interest in living and therefore are entitled to priority in life-saving. Such a $N$ position while it may be "sensitive" to differences hardly recommends itself as sensitive to the $\tilde{\delta}$ requirements of justice.

To add insult to injustice McKie et al's view also 옹 entails the conclusion that a million lives in Australia are almost always and almost inevitably more worth saving than a million lives in Ruanda. Or so they will be for the foreseeable future.

Figure 1, suggested to me by Eric Nord, illustrates the difference between the assumptions made bo $\%$ Singer, and the assumptions which lie behind me own position (which are also shared by Nord). It wit be seen that Nord and I assume that people's interest in staying alive will be maintained, even in the face of a poor prognosis or shortened life expectancy, until

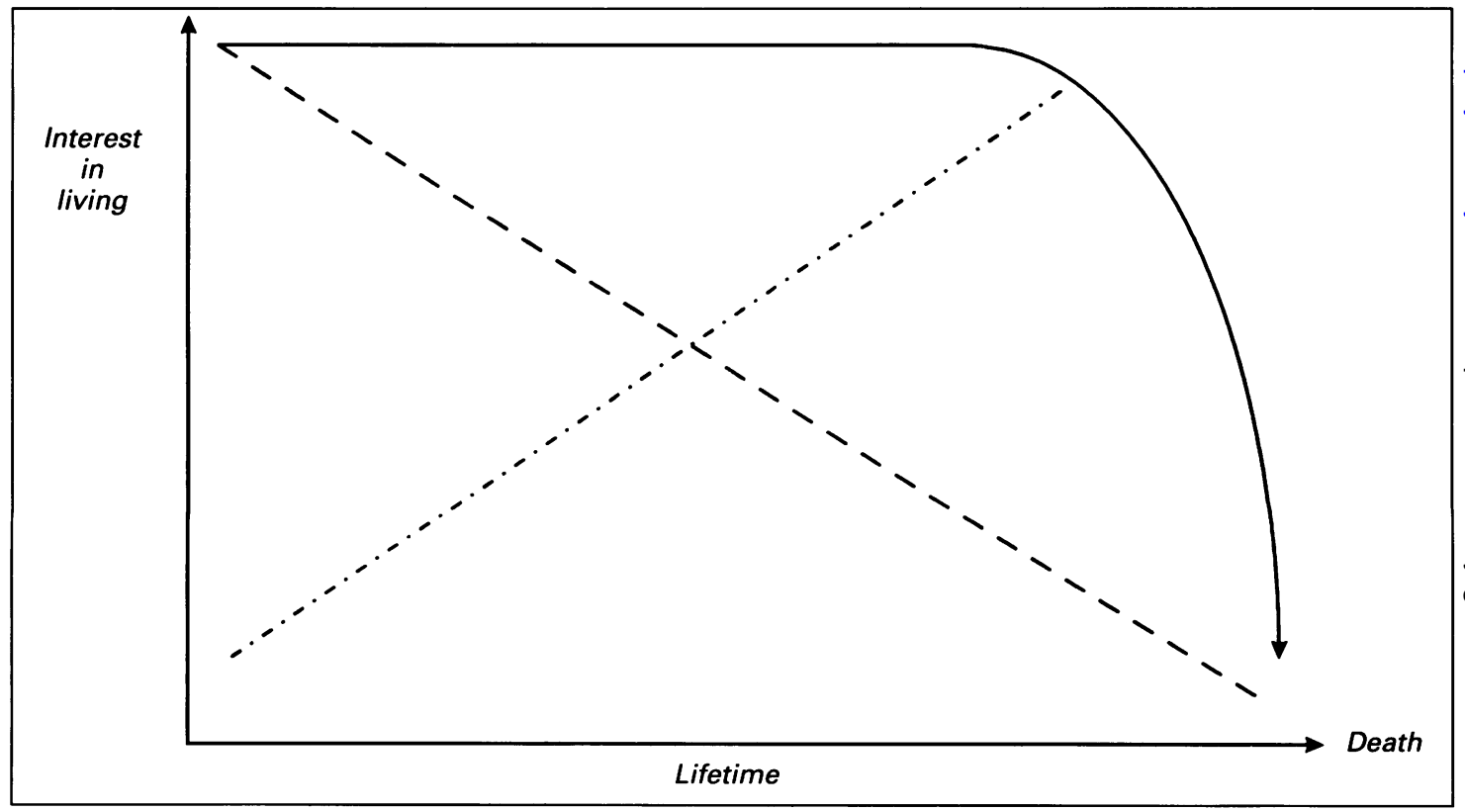


death is imminent. ${ }^{12}$ McKie et al assume that interest in staying alive declines in proportion to life expectancy. Interestingly, it is likely that just as interest in staying alive holds fairly constant until near the end, interest in cure is likely to increase steadily as death approaches. ${ }^{13}$

\section{Doing the most good}

A problem, which I have space here to note but not resolve, is one of how to interpret the requirement that we allocate resources for health care "so as to achieve the most good". McKie et al have one account of what it is to do the most good, but it is not the only one, nor I believe the most plausible. If each person matters equally and hence has an equal right to the care and consideration of the health care system of the society of which he or she is a member, then one of the things that might be thought to follow from this is that each person has the right to have his or her chance of benefit equally respected, whatever that chance may be. If you have a large chance of a large remission and I have a small chance of a small remission, then to treat us as equals is to give us each an equal opportunity of having our chance of our life, whatever chance that is. For if those with the better chance are always to be preferred this inevitably creates an aristocracy of the fortunate. Now this might be consistent with equal justice or rights for citizens, if fortune has no favourites. However, it is not only "common sense" that knows that some people are born lucky, our knowledge of genetic endowments has dramatically confirmed this. ${ }^{14}$

\section{World making}

McKie et al have a strong point and one with which I agree; the problem is it applies to an entirely different case. It might be true that people would prefer, when considering things abstractly, to create a world with higher rather than lower utility. If the veil is stipulated to precede identity then people might simply choose to be benevolent, knowing that what they choose cannot affect themselves adversely. What they will not have is rational-egoist reasons for such a preference, that is, not Rawlsian ones. If you tell people that what they choose will only affect others, they have no motive to be other than altruistic. But if you tell them it might affect themselves then, if the alternative is death, they need to be very confident about their chances of not dying prematurely as a result of what they choose.

\section{Life behind the veil}

There is an important feature of life behind the veil that is often imperfectly understood. What McKie et al say has some plausibility on the presumption that there is a natural lottery of health, where all behind the veil of ignorance have an equal chance of being the person with a poor QALY score. But, in the real world, a place for which McKie et al have a marked preference, all is not equal behind the veil. To mix metaphors, the dice are loaded, and this bears vitally on the question of what it is to do the most good.

The veil of ignorance is supposed to conceal identity not precede it, as I argued in the original paper. This means that behind the veil you are unaware of things about yourself which will be revealed by the lifting of the veil. They are hidden truths, they are not possible futures. Indeed so far from being possible futures they are impossible futures. There is no chance of their being true. So, for example, if the veil of ignorance conceals gender, then while it is true that behind it I do not know whether I am a man or a woman, it is not true that I have any chance of being anything other than a man when the veil is lifted. The point of the veil is that because I do not know my gender say, but by hypothesis I have one, I have no motive for advantaging one gender over another. Unless you are inflicted with illness when the veil is lifted or, by the lifting of the veil, and have an equal chance with everyone else of having that illness, it will not be true that under the QALY method of allocation you have "a $50 \%$ chance of getting a big utility gain". You will have no chance at all. I do not have a $50 \%$ chance of being pregnant when the veil is lifted or of having carcinoma of the cervix.

Genetic endowments are unlike contingent features such as poverty or riches, political power or success. Access to these might be altered by the rules of the society into which people will emerge, which are to be determined behind the veil of ignorance. However, genetic endowments are largely beyond the scope of human manipulation and these are just the sort of things that greatly influence people's QALY scores. ${ }^{15}$

To put the point another way, McKie et al treat the people behind the veil as candidates in a lottery in which the draw will take place at or after the lifting of the veil. All people behind the veil have a certain chance of winning or losing. However, unless identity occurs after the lifting of the veil, this is not the situation. Rather the lottery was run a long time ago and people are born with tickets that are already winning or losing tickets - they have no chance of either winning or losing with the tickets they possess because they already have won or lost. ${ }^{16}$

My point is that unless you have reason to suppose that you have a better than even chance of possessing a winning ticket, you will not vote for QALYs. This you cannot know.

In the first pair of papers we differed about Aristotle and slavery. The point concerned whether or not decisions behind a veil of ignorance are guaranteed to be just decisions. Whether or not they are depends crucially as we have seen, on assumptions made about the types of people who will decide. My 
point was that even the risk-averse might gamble on an unjust outcome if the chances were good enough that the injustice would benefit them. However, the material calculations are, even on Singer's figures, no better than one in four and on mine, no better than one in two. In both cases this is worse than the chances offered by so called "Russian Roulette" and I am happy to agree with McKie et al that Aristotle would accept my view of the gamble.

\section{QALYs and sensitivity}

McKie et al, despite priding themselves on the "sensitivity" of the QALY method, that is, its ability to use and even celebrate very small QALY advantages, in fact always talk as if the advantages are huge. So, for example, take the following passage which occurs in discussing my alleged error in computing life chances.

"... what the rational egoist is offered if treatment is allocated randomly is a $25 \%$ chance of the same big utility gain and a $25 \%$ chance of a small utility gain (life-saving treatment when you will die within a few days anyway)."17

But this is not the situation at all. What they should have talked about is not big and small utility gains comparing long life with a few days, but bigger and smaller utility gains which may be five days versus three days or three months versus twelve months. This is important for the following reasons: the way QALYs are currently likely to be used within any health care system operates at two levels, the macro and the micro. At the macro level they are likely to be used to discriminate between medical specialties, treatment programmes, or even hospitals which get, or are likely to get, better results in QALY terms. At the micro level they will be used, within say a given medical specialty, to choose between patients for treatment.

\section{The macro level}

At the macro level, what is likely to happen is that a given health care budget, let us say that of a nation state, will be divided between medical specialties, health regions, hospitals etc. On a fully consistent QALY method of application, some specialties with poor QALY results, such as palliative care, should get no money at all. Since this is unlikely to be politically acceptable, they will get smaller budgets than other specialties but all are likely to be funded (inconsistently of course) to some extent. Now behind the veil of ignorance, it will never be true that your chances of needing any particular specialty or living within a particular hospital region are 50/50. You may not have the information to calculate the odds but there will be odds. For example, in an aging population your chances when the veil has lifted of finding yourself in the second half of life are likely to be quite high. It $\stackrel{\mathbb{Q}}{\Omega}$ would not then be in your interests, if you were able tom calculate them, to prioritise the welfare of a minority $\overrightarrow{\bar{\sigma}}$. group within society (those with higher QALYs).

\section{The micro level}

If we now move to the micro level, things are even $\frac{\bar{\sigma}}{\overline{5}}$ worse. At the micro level, where money has been $\overrightarrow{\widetilde{\sigma}}$ allocated, as I say, to a particular medical specialty, 응 then it is likely that QALY calculations will involvew quite small differences. For example, in the treat- $\overrightarrow{0}$ ment, say of cancer or indeed of heart disease, the prognosis for people facing similar treatments will be different, but the differences are likely to be small. A ward of people waiting for coronary arteryळ bypass grafts for example, will have different QALY N scores but they will be small differences in all prob- + ability. Or, people awaiting treatment for carcinomaĩ of the cervix may have relatively similar QALYC scores. It seems plausible to suppose that such? people will not think that the problematic QALY calculations of economists and doctors should determine their priority for treatment. They are surely far more likely to regard themselves as "all being in the same boat" and therefore all deserving $\vec{\circ}$ of the same chance or fair share of opportunities fgro survival.

This brings us to the point on which McKie, co-authors and I are in agreement, namely on the disutility of any method of resource allocation which causes divisiveness within a society and a massive $\frac{\mathbb{Q}}{\mathbb{Q}}$ sense of injustice. A society which really bit the $\overrightarrow{\vec{F}}$ bullet on QALYs, as indeed any society believing in $\frac{0}{3}$ their ideology at all should do, would find itself $\underset{ }{J}$ saying to large cohorts of patients at the macro level: "We see no good reason to fund your care because it falls below a particular QALY threshold". The more this is done, the more at the micro level QALY: scores among those who will be treated are likely to 3 . be smaller rather than larger and the moral impera- $\delta$ tives for choosing on a QALY basis are likely to seem less advantageous to candidates for care, than the응 strong sense that all are in the same boat and each deserves his or her chance.

This is why I am driven back to the idea of a plausible view of the benefit to be derived from health care is not that that benefit is higher quantities 0 of quality life, but is a distribution to each citizen, to $N$ each claimant, of an opportunity that her unique and uniquely valuable life, that her unique and uniquelyo valuable existence, will be given equal weight. This $\mathbb{D}$ surely involves the acceptance of the idea that her $\stackrel{\text { ? }}{+}$ chance of continued existence (whether that chance 7 is small or large and offers long or short term survival) will be equally respected.

This is clearly a difference in worldview or $\overrightarrow{\mathbb{Q}}$ outlook. It is not susceptible to refutation in ao straightforward way, neither of course is the QALY or McKie et al view. For this reason McKie et al's 
approach and mine is rightly, at least predominantly, to set out our stall, because that is what it is. It is a stall in the market place of ideas which must attract customers by the appealing nature of the wares that it offers. A high part of that appeal of course is the claim that what each stall offers is, among other things, justice and respect for persons. It is the different conceptions of these ideas, embodied in those words, that will prove decisive.

\section{Acknowledgement}

In writing this paper I have benefited from the generous advice of David Colman, Soren Holm, Eric Nord, James Tooley and Simon Woods. All of them have helped me see more clearly the error of other peoples' ways. My own errors, not unnaturally, are still concealed from me.

Fohn Harris is Professor of Bioethics and Applied Philosophy and Research Director of The Centre For Social Ethics and Policy, University of Manchester.

\section{References and notes}

1 McKie J, Kuhse H, Richardson J and Singer P. Double jeopardy, the equal value of lives and the veil of ignorance: a rejoinder to Harris. Fournal of Medical Ethics 1996; 22: 204-8.

2 The original "pair" of papers were: Singer P, McKie J, Kuhse H, Richardson J. Double jeopardy and the use of QALYs in health care allocation and Harris J. Double jeopardy and the veil of ignorance - a reply. fournal of Medical Ethics 1995; 21: 144-50, and 151-7 respectively.

3 Just for the record my claim was that there was, by hypothesis, no better than a 50/50 chance of being the person with the highest (I should have said "higher" [of two]) interest in continued existence". If there is an error here I fail to see it. I was not talking of the percentage chance of a higher or lower utility gain.

4 See reference 2: Singer et al.
5 Not high, but higher, see below.

$6 \mathrm{OK}$, I should have said "more" not "most" but it doesn't affect the point.

7 There is clearly a slip here which involves a logical error since Singer et al move from the hypothesis that Aristotle might be disadvantaging himself to the certain knowledge that he would be.

8 My italics.

9 It may be that slavery is a fate worse than death but I doubt it.

10 A life-saving meal is only not worth eating if the life that it will save is not worth living. A life-saving meal is only less worth eating than a more desirable meal if they are equally available and will equally save the life in question.

11 This point was also missed by Singer in his exchange with Per Sundstrom. See Sundstrom P. Peter Singer and "lives not worth living" - comments on a flawed argument from analogy and Singer P. Straw men with broken legs: a response to Per Sundstrom. fournal of Medical Ethics 1995; 21: 35-8 and 89-90, respectively.

$12 \mathrm{I}$ invite readers to reflect on which set of assumptions are more likely to cohere with their own feelings about the value of life.

13 This suggestion I also owe to Eric Nord. The graph was drawn for me by Dr Nord "on the back of an envelope" in a bar in Buenos Aires. Any errors in transcription are mine alone.

14 The discussion of rival conceptions of what precisely the good is that we expect of health care is the subject of another paper entitled What is the good of health care (in Bioethics, in press).

15 Of course, as and when these things become manipulable by human beings, they will be more like political institutions and social organisation.

16 It is not like, so called, scratch cards which are already winning or losing tickets when issued because there the lottery is run when you buy the ticket. Having bought it and prior to scratching the card you are behind the veil of ignorance to be sure, but you have had an opportunity to buy a card that might be a winning or a losing card. In the lottery of health you sometimes have this chance but increasingly your genes, and behind the veil (unless all behind the veil are newborns), your age, will mean that your QALY scores are already rigged to a certain extent.

17 See reference 1: 206 